\title{
Masyarakat dan Kearifan Budaya Lokal (Bentuk Pela Masyarakat di Negeri Batu Merah Kota Ambon Pasca Rekonsiliasi)
}

\author{
Osbert Montana, Riris Loisa, Lusia Savitri Setyo Utami \\ Osbert.915150108@stu.untar.ac.id,Ririsl@fikom.untar.ac.id, Lusias@fikom.untar.ac.id \\ Fakultas Ilmu Komunikasi Universitas Tarumanagara
}

\begin{abstract}
The disastrous conflict that lasted for more than four years, not only worsened humanitarian relations or relations between religions, religious and community relations but also showed the crackdown in the lives of the Moluccas as a whole. This situation makes religion lose its momentum to make religion serve and liberate humans, a situation like this becomes a serious problem when religions must take a stand against pluralism. To avoid this conflict, tolerance is needed to maintain harmony between religious groups. Ambon, especially Ambon, is one of the regions that maintain tolerance and harmony with a population of 50\% Christian and 50\% Muslim. Before long, conflict differences were not a problem in Maluku because their communication was very strong and now Ambonese people are returning to how they used to interact, both with religionists and those with different religions. Almost the difference is no longer visible. The theory used in this research is Advance Negotiation Theory by Stella Ting-Toomey. This research was conducted with a qualitative method of case study and with the aim to find out the role of local cultural wisdom Pela in intercultural communication Ambon city religious communication was like what happened between people in Ambon who were of different religions and saw Pela forms of society after reconciliation so harmony can be maintained. Based on this research, it was found that there was a happy relationship or a very positive relationship between people (Christian-Islam) in Ambon and agreed to jointly reduce suffering so that there was no conflict like what had happened before.
\end{abstract}

Keywords: Intercultural Communication, Pluralism, Tolerance, Local of Wisdom

\begin{abstract}
Abstrak
Konflik Maluku yang berlangsung selama lebih dari empat tahun, tidak saja memperburuk hubungan-hubungan kemanusiaan atau hubungan lintas agama, hubungan agama dan masyarakat, tetapi juga meperlihatkan retaknya kehidupan masyarakat Maluku secara keseluruhan. Keadaan ini membuat agama kehilangan momentum untuk menjadikan agama yang melayani dan membebaskan manusia. Situasi seperti ini menjadi masalah serius ketika agama harus mengambil sikap terhadap pluralisme. Untuk menghindari konflik tersebut diperlukan sebuah toleransi untuk menjaga kerukunan antar umat beragama. Maluku khususnya Ambon menjadi salah satu daerah yang memelihara toleransi dan kerukunan dengan jumlah penduduk 50\% beragama Kristen dan 50\% lainnya beragama Islam. Dahulu, konflik perbedaan bukan sebuah masalah di Maluku karena komunikasi yang sangat kuat. Namun kini masyarakat Ambon kembali seperti dahulu dalam berinteraksi, baik dengan yang seagama maupun dengan yang berbeda agama. Perbedaan hampir sudah tidak terlihat lagi. Teori yang digunakan dalam penelitian ini adalah Teori Negosiasi Muka oleh Stella Ting-Toomey. Penelitian ini dilakukan dengan metode kualitatif studi kasus dan dengan tujuan untuk mengetahui peran dari kearifan budaya lokal Pela dalam komunikasi antar budaya umat beragama kota Ambon komunikasi seperti apa yang terjadi antara masyarakat di Ambon yang berbeda agama dan melihat bentuk-bentuk Pela masyarakat pasca rekonsiliasi sehingga kerukunan dapat terus terjaga. Berdasarkan penelitian ini didapatkan
\end{abstract}


hasil bahwa terjadi hubungan saling membahagiakan atau hubungan yang sangat positif antar masyarakat (Kristen-Islam) di Ambon serta bersepakat untuk bersama-sama mengurangi penderitaan sehingga tidak terjadi konflik seperti yang telah terjadi sebelumnya.

Kata Kunci: Komunikasi Antarbudaya, Pluralisme, Toleransi, Kearifan Budaya Lokal.

\section{Pendahuluan}

Sejak awal kehidupan sosial di Indonesia merupakan suatu ruang publik yang plural dan hal ini terlihat dalam berbagai segi kehidupan masyarakat, dan selalu menjadi masalah adalah pluralisme dalam bidang agama, ethnis dan sub-etnis.

Agust Ufie, Johan Pattiasina \& Samuel Patra (2017) menjelaskan bahwa kondisi negara Indonesia mengalami goncangan ditandai dengan terjadinya konflik bernuansa SARA. Salah satu dari konflik itu adalah konflik Maluku yang terjadi pada 19 Januari 1999. Lebih lanjut, pada waktu terjadi konflik kemanusiaan di Maluku pada tahun 1999 sebagian orang berpendapat bahwa pela dan gandong yang ada di Maluku sudah tidak lagi bisa digunakan sebagai pengikat antar kelompok masyarakat di Maluku.

Kekerabatan dan persaudaraan di Ambon saat ini secara alamiah memulihkan luka batin dan mempererat kembali tali persaudaraan yang sempat terputus. Kini Ambon telah bangkit dan menjadi contoh daerah perdamaian serta daerah yang mampu memperlihatkan kehidupan rukun masyarakatnya yang berlatar belakang berbeda.

Indonesia dikenal sebagai bangsa dengan kearifan budaya yang beranekaragam. Hal ini menjadi sebuah tantangan baru untuk masyarakat agar dapat selalu mempertahankan kearifan budaya lokal. Kearifan lokal memiliki nilai-nilai moral yang selalu diajarkan turun-temurun secara lisan maupun tulisan, warisan ini patut untuk dijaga karena masing-masing wilayah memiliki ciri khas kebudayaan masing-masing terhadap kearifan lokal yang terkandung di dalamnya.

Kearifan lokal pembawa perdamaian dan pemersatu hubungan persaudaraan yang dikenal dengan istilah Pela dan Gandong. Pela sebagai pranata sosial Maluku dapat memperlihatkkan bagaimana leluhur masyarakat Maluku tanpa memandang atau mempertimbangkan perbedaan-perbedaan yang ada diantara mereka baik berupa perbedaan kultural, sosial maupun perbedaan religi dan agama menurut Uneputty, 1996 (dalam Aponno 2017). Pela Gandong menurut Lokollo et al, 1997 (dalam Aponno 2017) merupakan perserikatan antara satu negeri atau beberapa negeri di Pulau Ambon, Leste serta Pulau Seram. Perserikatan ini didasarkan pada hubungan sejati isi dan tata laku perserikatan yang diatur dalam perjanjian baik lisan maupun tulisan, dimana setiap pihak harus berjanji untuk tunduk kepada perjanjian yang dimaksud sebagai dasar hukum bagi implementasinya dari waktu ke waktu. Hubungan Pela dan Gandong memiliki efek yang sangat penting bagi semua masyarakat untuk ikut serta dalam menjunjung kebersamaan dan juga menjaga hubungan.

Desa Batu Merah dikenal sebagai pusat pemukiman yang mayoritas penduduknya beragama Muslim di Kota Ambon. Pada masa konflik Ambon berdarah (antara Islam dan Kristen), negeri Batu Merah menjadi area konflik terpanas dan saat itu banyak rumah serta rumah ibadah seperti Gereja dan Masjid yang hancur terbakar. Kini dalam kehidupan sehari-hari, masyarakat di Batu Merah diikat dengan perjanjian Pela dan Gandong sebagai budaya mereka. 
Lebih lanjut, dalam mengatasi konflik terdapat lima gaya manajemen untuk mengelola konflik, yaitu: 1) menghindar (Avoiding- $A V$ ) orang akan menghindari pertukaran yang tidak menyenangkan dengan orang lain dan berusaha menjauhi ketidaksepakatan, 2) menurut (Obliging-OB) orang akan berusaha memuaskan kebutuhan orang lain serta akan sepakat dengan saran baru atau saran dari orang lain, 3) berkompromi (Compromising-CO) setiap individu akan berusaha untuk menemukan jalan tengah dalam mengatasi jalan buntu serta menggunakan pendekatan memberi-menerima sebagai cara untuk mencapai kata kompromi, 4) mendominasi (Dominating-DO) perilaku-perilaku yang menggunakan wewenang, pengaruh, atau keahlian dalam menyampaikan sebuah ide dalam mengambil keputusan, dan 5) mengintegrasikan (Integrating-IN) cara untuk menemukan solusi dari sebuah masalah dan sangat membutuhkan perhatian yang sangat tinggi untuk orang lain (West \& Turner, 2008).

Penelitian ini dapat dikatakan sebagai contoh bingkai pemersatu hubungan antara-masyarakat, antar-kelompok, antar-agama di Maluku agar lebih dilestarikan dan diperhatikan kebudayaannya sehingga Maluku mampu menjadi sebuah provinsi yang damai walaupun di dalamnya masih banyak sekali terdapat sebuah perbedaan yang ada di dalam masyarakat, serta menjadi suatu contoh kepada kota-kota besar lain di Indonesia. Penelitian ini dilakukan untuk memberi informasi kepada pembaca mengenai sebuah cerita perdamaian dan persaudaraan yang tidak bisa dibaca di buku sejarah. Penelitian ini menunjukkan bahwa di dalam konflik tidak ada yang diuntungkan dan kisah Ambon sebenarnya tidak perlu terjadi karena dari awal masyarakat Ambon sudah hidup damai serta saling menghargai satu sama lain agar dapat tercipta suatu kebersamaan yang erat khususnya Maluku dapat terlepas dari masalah-masalah SARA yang mungkin akhir-akhir ini sering dan dapat terjadi karena Ale Rasa Beta Rasa (Kamu Rasa, Saya Rasa).

Kerukunan dalam Kamus Besar Bahasa Indonesia yang diterbitkan oleh Departemen Pendidikan dan Kebudayaan, diartikan sebagai perihal hidup rukun dengan "rasa rukun" dan "kesepakatan". Lebih lanjut, dalam PMB No. 8 dan 9 Tahun 2006, Bab I pasal 1 ayat 1 dalam pemeliharaan kerukunan umat beragama, pemberdayaan forum kerukunan umat beragama, dan pendirian rumah ibadat dinyatakan bahwa: kerukunan umat beragama yang dilandasi toleransi, saling pengertian, saling menghormati, menghargai kesetaraan dalam pengamalan ajaran agamanya dan kerjasama dalam kesetaraan dalam pengalaman ajaran agamanya dan kerjasama dalam kehidupan bermasyarakat, berbangsa dan bernegara di dalam Negara Kesatuan Republik Indonesia berdasarkan Pancasila dan Undang-Undang Dasar Negara Republik Indonesia Tahun 1945.

\section{Metode Penelitian}

Penelitian ini menggunakan pendekatan deskriptif-kualitatif. Penelitian kualitatif merupakan metode penelitian yang berlandaskan pada filsafat positivisme, yang digunakan untuk meneliti pada kondisi obyek yang alamiah, (sebagai lawannya adalah eksperimen) dimana peneliti adalah sebagai instrumen kunci, pengambilan sampel sumber data dilakukan secara purposive dan snowball, teknik pengumpulan dengan triangulasi (gabungan), analisis data bersifat induktif/kualitatif, dan hasil penelitian kualitatif lebih menekankan makna dari pada generalisasi (Sugiyono, 2011). 
Pada umumnya, penelitian kualitatif deskriptif berupaya keras supaya pembahasan yang didapat lebih cenderung kualitatif daripada kuantitatif, dengan mendekati makna dan ketajaman analisis-logis dan juga dengan cara menjauhi statistik "sejauh-jauhnya". Dengan demikian, kualitatif deskriptif diterima sebagai salah satu tipe penelitian kualitatif. Lebih lanjut, penelitian sosial menggunakan format deskriptif kualitatif bertujuan untuk mengkritik kelemahan penelitian kuantitatif (yang terlalu positivisme), serta juga bertujuan untuk menggambarkan, meringkaskan berbagai kondisi, berbagai situasi, atau berbagai fenomena realitas sosial yang ada di masyarakat yang menjadi objek penelitian, dan berupaya menarik realitas itu ke permukaan sebagai suatu ciri, karakter, sifat, model, tanda, atau gambaran tentang kondisi, situasi, atatupun fenomena tertentu (Bungin, 2011).

Penelitian ini menggunakan metode penelitian studi kasus. Studi kasus adalah salah satu metode penelitian ilmu-ilmu sosial. Menurut Yin (2008) studi kasus adalah sebuah metode penelitian yang digunakan untuk menjawab pertanyaan why (mengapa) dan how (bagaimana) yang ada di dalam sebuah penelitian yang memiliki sedikit kontrol atas sebuah kejadian yang berfokus pada fenomena kontemporer yang memiliki konteks dengan kehidupan nyata dari individu, komunitas, kelompok, maupun organisasional.

Pengumpulan data dalam penelitian ini dilakukan melalui studi pustaka, observasi, wawancara, dan penelusuran online. Untuk melengkapi penelitian ini maka penulis akan menggunakan teknik menganalisis data menurut Strauss dan Corbin (dalam Emzir, 2012), analisis data kualitatif terdiri atas tiga jenis pengodean (coding) utama, , yaitu (1) pengodean terbuka (open coding), (2) pengodean berporos (axial coding), dan (3) pengodean selektif (selective coding). Peneliti menggunakan triangulasi dengan sumber data dan triangulasi dengan metode sebagai teknik keabsahan data pada penelitian ini.

\section{Hasil Temuan dan Diskusi}

Temuan dalam penelitian ini: 1) Pengamatan sebelum lapangan penulis lakukan terhadap pemberitaan di beberapa portal berita online dalam memberitakan perkembangan mengenai kehidupan masyarakat beragama di Kota Ambon. Berikut adalah hasil observasi penulis terhadap dua portal berita online (BBC.NEWS dan KOMPAS.COM) dan ada dua video yang bersumber dari media Youtube (CAMEOPROJECT dan KOMPASTV), 2) Pengamatan langsung di lapangan penulis lakukan mengetahui langsung kearifan budaya lokal Ambon yang disebut dengan Pela, lalu melakukan observasi langsung di daerah Desa Batu Merah dengan melihat lokasi serta kegiatan-kegiatan masyarakat setempat, serta lebih lanjut mencari profil desa Batu Merah untuk mengetahui informasi secara lebih detail dan menyeluruh.

Lebih lanjut, hasil temuan dalam penelitian ini akan penulis tuliskan dalam beberapa sub-pembahasan.

Pela

Sejarah Pela di Maluku Tengah tidak dapat dilepaskan dari keterkaitannya dengan masyarakat di Seram. Perkembangan Pela berhubungan erat dengan migrasi kelompok suku yang disebabkan perpecahan. Hal itu menyebabkan bertambahnya jumlah penduduk tetapi terbatasnya sumber daya alam dan mengakibatkan peperangan antar-suku sebagai upaya mempertahankan diri. Pela sebagai ikatan 
sosial yang memiliki latar belakang historis yang sangat panjang. Ada pendapat bahwa hubungan pela telah bertumbuh jauh sebelum datangnya agama Islam dan Kristen. Hal itu beralasan setidak-tidaknya jika melihat sejarah, pela dikenal dalam bentuk awal sebagai bentuk persekutuan antar individu dalam kelompok atau bisa saja dalam masyarakat suku. Jadi, bentuk dari itu disebut bentuk pela yang paling mendasar yang dalam seiringnya waktu dapat mengalami perubahan dan mengikuti perkembangan masyarakat saat ini. Pela menjadi kekuatan yang mampu mendorong terciptanya suatu hubungan yang lebih manusiawi di atas basis kultur masyarakat. Ketika orang berbicara tentang mambangun kehidupan masyarakat maka yang dimaksud adalah kehidupan diantara masyarakat yang berbeda agama, antara Islam dan Kristen. Selain itu sebagai sistem persahabatan, persaudaraan atau juga suatu sistem persekutuan yang dikembangkan antara seluruh penduduk asli dari dua negeri atau lebih. Mengharuskan adanya hubungan yang teratur antara dua kelompok di tingkat desa yang berpela dan inti dari persaudaraan diuji secara berkala. Ketika sebuah negeri muslim membantu kristen anggota pela mereka dan sebaliknya dan biasabantu itu bukan sekedar bantuan ekonomi saja, tetapi lebih kebantuan komitmen yang pasti itu untuk bantuan persaudaraan masyarakat secara keseluruhan.

\section{Pela Desa Batu Merah}

Batu Merah memiliki Pela dengan Passo. Berawal dari pada saat tahun 1500an itu, Maluku, Irian dan sebagian Filipin itu dikuasai oleh kerjaan daru sultan ternate. Maluku sendiri dibawah kekuasaan Sultan Ternate, di suatu ketika di bawah kekuasaan sultan itu dianjurkan untuk setiap tahun itu membayar upeti atau pajak ke kerajaan. Ketika itu batu merah mewakili patasiwa dan paso itu mewakili patalima bertolak menuju ternate dengan kendaraan dulu itu bernama kora-kora, perahu tapi namanya kora-kora. Itu semua negeri-negeri dibawah kekuasaan sultan ternate itu membawa upeti kesana dan suatu ketika semua sudah membawa upeti kesana dan sekembalinya dari ternate pasukan kora-kora ini semua mendapat musibah yaitu gelombang pasang dilautan dan semua itu aman kecuali kora-kora dari passo mendapat musibah dan tenggelam dihantam ombak. Ketika orang-orang passo itu meminta tolong, tidak ada semua yang mendengar, yang ada itu hanya pasukan korakora Batu Merah. Ketika itu dengan spontanitas mereka berteriak, kita harus menolong orang itu tetapi kita belum tahu siapa yang kita tolong. Ketika sampai pertolongan itu, perahu mereka hancur lalu diangkat masuk kedalam perahu batu merah, lalu sama-sama kita jalan dan lagi itu dekat dengan pulau buruh. Kita sampai disana, kita singgah dan makan bekal-bekal batu merah yang ada. Itu sekarang ini ada satu kampung namanya Kampung Pela dan desanya sampai saat ini bernama desa pela di pulau buruh. Konon disana itu desanya batu merah dan paso punya sampai hari ini. Setelah disitu kita buka bekalnya orang batu merah, bekal yang tersisah itu sagu, kelapa sama ikan dan dulu itu sebutannya sagu salempeng patah dua, satu buat batu merah satu buat paso dan ada ikatan disitu. Ikanpun satu dipatah dua dan kelapapun juga seperti itu. Setelah selesai makan dengan spontanitas juga orang paso ini mengangkat suara, orang batu merah ini bagaimana kalo kita orang angkat sumpah kalo batu merah ini adalah pela kakak dari kita, dan spontanintas juga orang batu merah menyambut itu dengan angkat sumpah bahwa kalian adalah adik kita. Angkat sumpah itu lalu mereka ambil batu karang, dayung yang mereka punya itu di hadang dua gini lalu batunya dibalik tutup dua itu. Selesai balik batu itu tangan semua berdarah itu disatukan, dengan darahnya itu mereka menyatukan dan diangkat sumpah. Dari sumpah itu ada 3 perjanjian orang batu merah menggangkat paso 
sebagai pela adik dan paso menggankat betu merah sebagai pela kakak, dan 3 komitmen ini bahwa batu merah dan passo tidak boleh baku musuh, baku kawin dan harus saling tolong menolong sampai dengan hari ini.

\section{Pela Sebagai Local Wisdom}

Dalam kebudayaan terdapat elemen subjektif yang dibentuk oleh manusia di masa lalu dalam meningkatkan kemungkinan untuk bertahan hidup di antara mereka agar mampu berkomunikasi satu sama lainnya, dikarenakan mempunyai kesamaan bahasa serta mereka hidup dalam waktu dan tempat yang sama. Dengan kata lain, penulis mengartikan pela merupakan local wisdom yang sudah ada sejak lama hingga saat ini.

Komunikasi Antar Budaya yang Berporos Pada Pela

Gambar 4.5 Komunikasi Antar Budaya yang Berporos Pada Pela

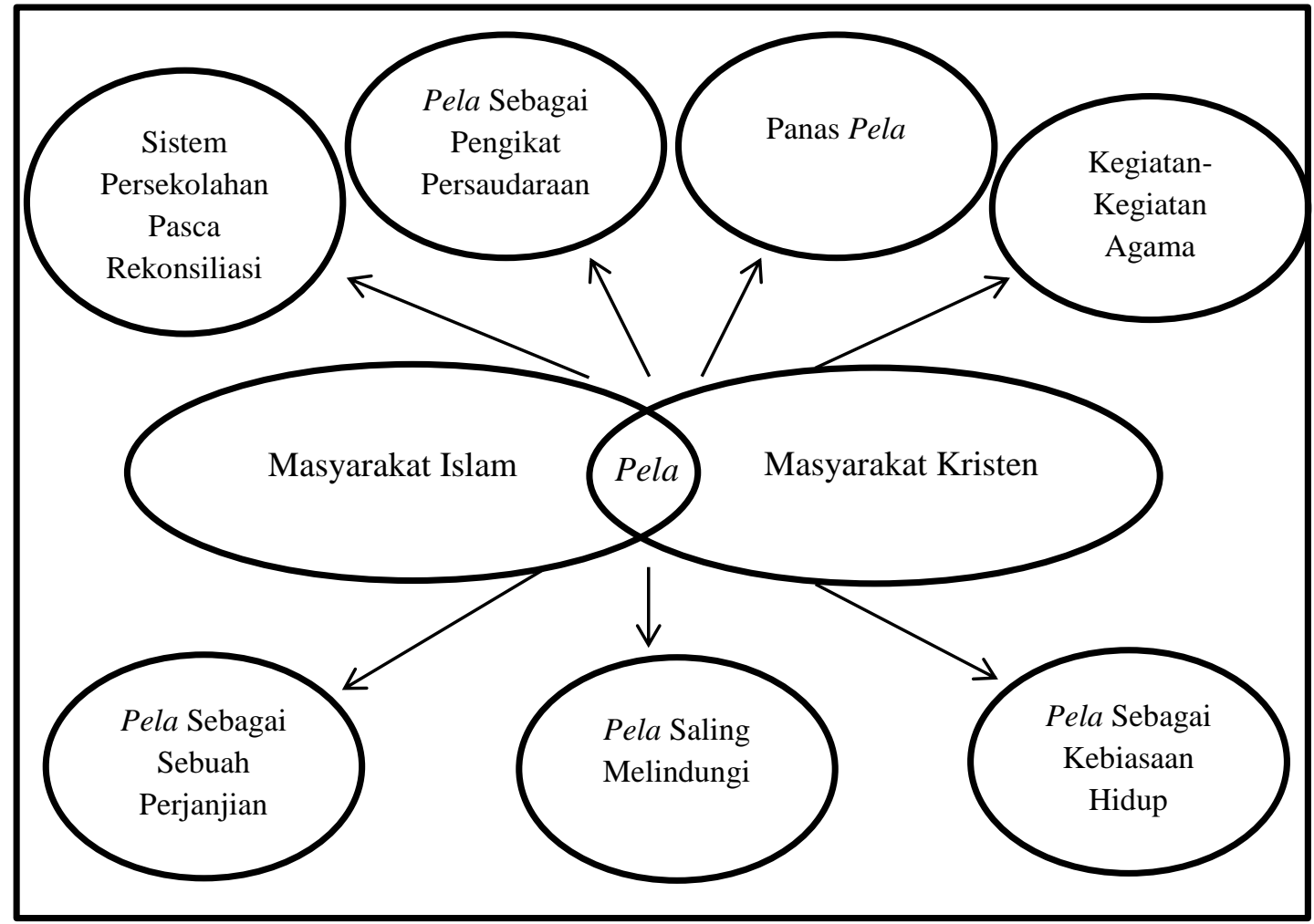

\section{Indonesia Bukan Hanya Jakarta}

Dalam Pluralisme menjelaskan bahwa sebuah masyarakat demokratis hanya mungkin dibangun ketika orang sadar akan fakta perbedaan di dalam masyarakat, dan sadar pula akan adanya suatu kehendak besama yang tidak bisa direduksi kepada kehendak mayoritas. Dalam kata lain, penulis mengartikan Indonesia dibangun bukan hanya dengan Jakarta saja melainkan banyak daerah-daerah lainnya. Indonesia terkenal dengan keberagamannya dan tidak monoton hanya di satu daerah.

\section{Pela Sebagai Proses Komunikasi}

Teori Negosiasi Muka menjelaskan budaya memberikan sebuah bingkai interpretasi lebih besar di mana sebuah muka serta gaya konflik dapat dipertahankan 
dan diekspresikan secara bermakna. Teori Negosiasi Muka yang dikembangkan oleh Stella Ting-Toomey merupakan teori yang secara eksplisit dapat memperlihatkan bahwa orang dari budaya lain dengan "muka" memiliki pemikiran yang berbeda dengan orang dari budaya lain dengan "muka" yang berbeda. Hal ini membuat setiap orang dalam menghadapi konflik memiliki cara yang berbeda. Dalam kata lain, penulis mengartikan Pela memeberikan interpretasi yang lebih besar di mana muka dan gaya konflik dapat diekspresikan dan dipertahankan secara bermakna serta menghadapi konflik dengan cara yang berbeda. Pela sebagai proses komunikasi dalam menghadapi konflik dengan cara menghindar, menurut dan kompromi.

\section{Simpulan}

Kini pela tidak hanya merupakan nilai simbolik budaya saja tetapi sudah menjadi sebuah paham dari agama. Selama upacara kegiatan panas pela selalu diperbaharui, selama upacara dalam gereja dan masjid serta kesatuan Islam dan Kristen yang percaya kepada satu Allah diaktifkan, kehadiran dari semua masyarakat atau negeri mensimbolkan totalitas dari masyarakat ambon dan penegasan sanksi adat dalam tradisi pela menegaskan kehidupan yang baru dalam tradisi yang lama. Pela dapat membangun format baru dalam membingkai hubungan antaragama dalam konteks plurasime di Maluku, dapat membangun Maluku Baru yang bersatu, berkeadilan, berkedamaian, serta menjunjung tegaknya kemanusiaan.

\section{Ucapan Terima Kasih}

Ucapan terima kasih penulis persembahkan kepada setiap narasumber yang bersedia meluangkan waktunya untuk penulis wawancarai dan telah memberikan informasi kepada penulis selama proses pengumpulan data di lapangan. Penulis juga mengucapkan terima kasih kepada dosen pembimbing, co-pembimbing serta orangtua penulis yang telah memberikan segala dukungan dalam proses penelitian ini sehingga penulis dapat menyelesaikan penelitian ini tepat pada waktunya.

\section{Daftar Pustaka}

Agust Ufie, J. P., \& Samuel Patra. (2017). Prosiding Seminar Nasional "Semangat Hari Pattimura dan Kebangkitan Nasional untuk Bhinneka Tunggal Ika.

Aponno, E.H. (2017). Budaya Lokal Maluku "Pela Gandong" dalam Konteks Perilaku Organiasi. Jurnal Manajemen.

Bungin, Burhan. (2011). Penelitian Kualitatif. Jakarta: Kencana Predana Media Group.

Emzir. (2012). Metodologi Penelitian Kualitatif: Analisis Data. Jakarta: PT RajaGrafindo Persada.

Lokollo, J. E., et al. (1997). Seri Budaya Pela Gandong dari Pulau Ambon. Ambon: Lembaga Kebudayaan daerah Maluku.

Mulyana, Deddy. (2004). Metodologi Penelitian Kualitatif. Bandung: PT Remaja Rosdakarya.

Paramita, S., \& Wulan, S.P. (2016). Komunikasi Lintas Budaya dalam Menjaga Kerukunan antara Umat Beragama di Kampung Jaton Minahasa. Jurnal Pekommas. 
Peraturan Bersama Menteri Agama PMB No. 8 dan 9 Tahun 2006, Bab I pasal 1 ayat 1

Ruhulessin, John Chr. (2005). Etika Publik : Menggali dari Tradisi Pela di Maluku. Salatiga: Universitas Kristen Satya Wacana.

Sugiyono. (2011). Metode penelitian Kualitatif. Bandung: Alfabeta.

Uneputty, T. J. A. (1996). Perwujudan Pela Dalam Kehidupan Sosial Masyarakat Maluku. Ambon: Bagian Proyek Pengkajian dan Pembinaan Nilai-nilai Budaya Maluku.

West, R., \& H. Turner, Lynn. (2008). Pengantar Teori Komunikasi: analisis dan aplikasi (Edisi ke-3). Jakarta: Salemba Humanika.

Yin, K. R. (2008). Studi Kasus; Desain dan Metode. Jakarta: PT RajaGrafindo Persada.

https://kbbi.kemdikbud.go.id/entri/kerukunan diakses pada tanggal 29 September 2018, Pukul 15.12 WIB. 